\title{
DE TWEEDE KAMER STATEN-GENERAAL OVER HET WETSONTWERP OP HET LEVENS- VERZEKERINGSBEDRIJF.
}

Over bovengenoemd wetsontwerp werd in dit tijdschrift (jaargang 1912 blad. 841-861) reeds gehandeld door $\mathrm{mr}$. A. W. Wichers. Het ongunstig oordeel van dezen schrijver wordt door het Voorloopig Verslag der Tweede Kamer Staten-Generaal volkomen bevestigd. Aangezien ik mij met deze dubbele veroordêeling geheel kan vereenigen zal ik mij thans bepalen tot eenige aanteekeningen op dit verslag. Het is trouwens zoo uitvoerig en duidelijk gesteld, dat van aanvulling en nadere opheldering geen sprake behoeft te zijn. Daarbij betreft het een onderwerp, dat vér blijft van de politiek in engeren zin, zoodat alle partijen eendrachtig kunnen samen werken, om het hooge sociale belang, dat bij het wetsontwerp betrokken is, onder de oogen te zien en het daarin behandelde vraagstuk tot behoorlijke oplossing te brengen. Daartoe wensch ik in deze bladzijden, in aansluiting met mijne vroegere beschouwingen over dit onderwerp (zie "de Economist" voor November 1908) een bijdrage te leveren.

In het Verslag worden de bezwaren tegen het wetsontwerp samengevat in enkele hoofdpunten, die wij hier achtereenvolgens zullen nagaan.

a. Volksverzekering. Met recht wordt er op gewezen dat dit voorname onderwerp in het wetsvoorstel geheel wordt voorbijgegaan. Dit gemis treft te meer, omdat de beweging hiervan is uitgegaan. De staatscommissie van 1892 werd voor dit doel samengesteld, maar achtte het niet mogelijk haar taak behoorlijk te volbrengen zonder tevens het geheele levensverzekeringsbedrijf te regelen. Zoo werd in 1895 haar mandaat uitgebreid, maar bleef in zoover de oorspronkelijke bedoeling van haar samenstelling bestaan, 
dat in het door haar aangeboden wetsontwerp de zaak der volksverzekering afzonderlijk werd geregeld.

Die regeling is te vinden in $\S 6$, bevattende de artikelen 65-69, van haar voorstel. $\mathrm{Zij}$ kan met geringe wijziging in het thans hangende wetsontwerp worden overgebracht; daarmede wordt voldaan aan den wensch van "vele leden" dat deze gewichtige zaak niet door een afzonderlijke wet, welke in een afzienbaren tijd toch niet ware te wachten, maar in het nu voorgestelde ontwerp geregeld zou worden. Daartoe is echter een indeeling in paragrafen, welke thans ontbreekt, onmisbaar.

b. Buitenlandsche matschappijen. In afwijking van de opmerkingen in het Verslag en ook van de bepaling in het wetsontwerp omtrent dit punt, acht ik hier strenge maatregeling overbodig, althans tegenover die landen, waar een wettelijke regeling bestaat. En dat is het geval met nagenoeg alle landen, waarvan maatschappijen haar werkkring over ons land hebben uitgebreid.

Met name in het Duitsche Rijk en in Frankrijk zijn zulke strenge wetten op het bedrijf in werking gebracht, dat nederlandsche maatschappijen, die in deze landen succursalen hadden, gedwongen waren ze op te heffen, omdat zij niet aan de daar gestelde eischen van geldbelegging en reserveberekening konden of wilden voldoen. Aangezien het toezicht in die landen zich ook uitstrekt over de buitenlandsche succursalen, behoeft men geen vrees te koesteren, dat zij in bevoordeelde concurrentie zullen treden met de binnenlandsche maatschappijen. Want al moge ten ontzent het toezicht in den geest van het Verslag nog zoo worden verscherpt, nooit zal het zoo streng worden als in de genoemde landen. Veilig kan men derhalve die concurrentie hier toelaten; zij zal het bedrijf eer tot voordeel dan tot nadeel strekken. Het storten van een waarborgsom is voor groote buitenlandsche maatschappijen geen bezwaar; zij hebben toch zulke aanzienlijke kapitalen als premie-reserve, dat zij gemakkelijk daarvan een deel aan de nederlandsche regeering in bewaring kunnen geven. Dit geschiedt nu ook door nederlandsche maatschappijen, die in het buitenland werken. Het wordt dan beschouwd als een depôt, dat in veilige handen is geplaatst, en behoorlijke rente afwerpt. 
c. Overdrachten samenvoeging. In het wetsontwerp ontbreken bepalingen, die hierop betrekking hebben. Terecht wordt hierop in het Verslag de aandacht gevestigd. Dit treft te meer, omdat in den laatsten tijd ten onzent herhaaldelijk een dergelijke overdracht of samenvoeging plaats had, en na de invoering eener wet menige nieuwe is te wachten. Zonder wettelijke bepalingen zijn geïnteresseerden aan de willekeur van concerteerende maatschappijen overgelaten. Ook hier kan ik verwijzen naar het ontwerp der staatscommissie van 1892, waar in $\S 5$ deze zaak op voldoende wijze is geregeld.

d. Eischen te stellen bij de oprichting van matschappijen. Art. 2 van het wetsontwerp stelt den eisch van storting van een kapitaal bij de oprichting eener nieuwe maatschappij, maar ook aan de bij de invoering der wet bestaande maatschappijen. Voor binnenlandsche maatschappijen wordt dit kapitaal op hoogstens één honderd duizend gulden gesteld, waarlijk, een peulschilletje voor de grootere maatschappijen! Het kleinst te storten bedrag is vijftig duizend gulden „of zooveel meer als de wiskundige reserve bedraagt". Deze laatste bijvoeging heeft echter geen zin, want de kapitaalsstorting staat met wiskundige reserve in geen verband. De eerste is een waarborg van zeer betrekkelijke waarde, de tweede een onmisbaar vereischte.

e. Insolventie. Vooral omtrent deze gewichtige aangelegenheid worden in het Verslag behartigingswaardige wenken gegeven. Want in het wetsontwerp wordt het geheel voorbijgegaan. Zoo wordt er terecht op gewezen, dat levensverzekering-maatschappijen nog jaren lang kunnen voortgaan met betalen, nadat het evenwicht tusschen activa en verplichtingen is verbioken. Men behoeft van sommige maatschappijen slechts de jaarlijksche balans met aandacht na te gaan, om zich van de waarheid dezer uitspraak te overtuigen. Wat baat het bij wijze van reclame op een hoog reservebedrag te wijzen, wanneer een nauwkeurige berekening leert, dat het lang niet voldoende is om tegen de aangegane verplichtingen op te wegen? Wat bewijst een hooge storting op de premiereserve, wanneer zij blijft beneden de rente van het aanwezige bedrag, genomen op den voet, naar welken die reserve berekend is, en dat 
terwijl de maatschappij beweert in bloeienden toestand te verkeeren? De deskundige herkent aan dergelijke teekenen den onfeilbaar te wachten ondergang, al kan het nog jaren duren eer de kenteekenen van den „krach" zich naar buiten vertoonen. De deskundige laat zich in deze niet verblinden, noch door de pracht van opgerichte paleizen, noch door schitterende feesten en royale geschenken, allerminst door de voorspiegeling van groote winsten. Hij ziet in die verschijnselen de kenteekenen van den onvermijdelijken ondergang, al kan deze door het aanwenden van kunstgrepen nog jaren lang worden uitgesteld. Een dezer kunstgrepen is het verlagen der tarieven, waardoor vele nieuwe verzekeringen worden gelokt; de premiën moeten dan dienen, niet om de reserve voor deze nieuwe contracten te vormen, maar om de vervallen uitkeeringen op vorige contracten te voldoen. Terecht wordt in het Verslag op dergelijke misbruiken gewezen; misbruiken, ontstaan en bevorderd door den wetteloozen toestand, waarin het bedrijf zich ten onzent bevindt. In het wetsontwerp wordt geen enkele maatregel hier tegen genomen. $\mathrm{Al}$ werd dit in werking gebracht, de misbruiken zouden onbelemmerd voortwoekeren, tot eindelijk de ineenstorting plaats heeft tot schade van de verzekerden, waaronder zoovele weduwen en weezen!

Toen ik voor eenige jaren aan een der sommiteiten op dit gebied vroeg, of ook hij niet van oordeel was dat het faillissement eener levensverzekering-maatschappij een groote maatschappelijke ramp zou zijn en hij mij met onverschilligheid antwoordde: "niet meer dan van eenige andere even groote maatschappij", begreep ik eerst recht, hoe dringend noodig een wettelijke regeling van het bedrijf is, en hoe alle krachten moeten worden aangewend om haar tot stand te brengen. Van daar ook de teleurstelling van alle welmeenenden, toen van regeeringswege zulk een on voldoend ontwerp werd aangeboden. Juist hieruit blijkt het onvoldoende van dit ontwerp, dat het werd geprezen door hen, die voor de maatschappij, die zij besturen, van een strengere regeling alles hebben te duchten. Dit vooral had de regeering bij de samenstelling en toelichting van haar ontwerp tot waarschuwing moeten strekken! Gelukkig 
althans, dat de Tweede Kamer die taak op zich neemt en met zooveel kracht wijst op de gevaren, die uit een onvoldoende regeling voortspruiten.

f. Verzekeringskamer. In art. 9 van het ontwerp wordt voorgeschreven, dat tot bijstand in de uitvoering van deze wet een verzekeringskamer $\mathrm{k}$ a $\mathrm{n}$ worden ingesteld. Terecht wordt in het verslag opgemerkt, hoe het dus van het persoonlijk inzicht van een minister zou afhangen, of zulk een kamer er al of niet zal zijn. De één kan haar, overtuigd van haar noodzakelijkheid, oprichten, maar zijn opvolger haar overbodig achtende, weer afschaffen en zoo kan zij in voortdurende wisseling van bestaan verkeeren. Bestaat de kamer niet, dan blijft de geheele wet zonder eenige uitwerking. Want dan moeten door de maatschappijen bij de regeering wel statuten en verslagen worden ingeleverd, doch deze blijven daar rusten zonder eenig gevolg. Minstens eens in de tien jaren moet een onderzoek worden ingesteld aangaande de juistheid der ingediende gegevens, doch ook dit onderzoek blijft zonder eenig gevolg. Nauwkeurig heb ik nagegaan hoe op grond dezer wet aan bestaande misbruiken een einde kan worden gemaakt, maar ik heb daarin geen enkel afdoend middel gevonden. Even als thans zal een geïnteresseerde, zich verongelijkt achtende, zich te vergeefs tot eenige macht wenden, hetzii om redrès van grieven, hetzij om een onderzoek uit te lokken, nergens zal hij gehoor vinden. Hij kan zich tot een rechtbank wenden of tot den hoogen Raad, zelfs in hoogste instantie tot de Koningin, onverbiddelijk zal hij als tot dusver worden afgewezen op grond, "dat in de wet geen termen zijn te vinden om aan zijn verzoek te voldoen".

In elk geval moet dus, opdat de wet eenige werking ten goede zal hebben het onzekere $\mathrm{k}$ a $n$ van art. 9 vervangen worden door het zekere $\mathrm{zal}$. Maar zelfs dan nog blijft hoogst onzeker, of de wet ten dien opzichte eenigen waarborg voor de richtige naleving van gesloten contracten, ook voor een verre toekomst, zal geven. Want die op te richten verzekeringskamer krijgt geen macht tot handelend optreden; te dien opzichte bepaalt art. 10 slechts: „de bevoegdheid en de werkkring van de verzekeringskamer worden nader bij algemeenen maatregel van bestuur geregeld". 
Ook hier blijft dus onzekerheid, zoolang niet vaststaat, welke macht aan de kamer wordt gegeven. Zal deze eenigen invloed ten goede hebben, dan moet die bevoegdheid in de wet zelf worden vastgelegd, en niet blijven overgelaten aan de wisselende inzichten van elkander opvolgende ministers.

Krachtig wordt dan ook op dergelijke gronden in het Verslag tegen deze regeling opgekomen. Daarin toch lezen wij het volgende: "met het oog op een en ander behooren in de wet voorschriften voor te komen, krachtens welke, op aanvraag van verzekeringnemers of op verzoek van een aan te wijzen Rijksorgaan (verzekeringskamer) een onderneming door een rechterlijke autoriteit, hetzij dan door den gewonen rechter, hetzij een administratieven rechter, onder voogdij kan worden gesteld, opdat het beheer, in het belang der verzekeringnemers, door bewindvoerders worde gevoerd en naar omstandigheden tot liquidatie of tot overdracht der onderneming aan een andere maatschappij wordt overgegaan, dan wel, na reorganisatie, tot voortzetting worde besloten". En verder "voorts behoort zeer stellig ook een nadere omschrijving van de tak en de bevoegdheid der Kamer, in de wet thuis; dit punt, dat voor de werking der wet van essentiëel belang is, kan niet geheel aan een Koninklijk besluit worden overgelaten; de maatschappijen hebben er recht op, dat wettelijk vaststa, hoever de bevoegdheid tot inmenging der verzekeringskamer gaat. De bepalingen, welke dit wetsontwerp over de verzekeringskamer bevat, hadden evengoed ongeschreven kunnen blijven".

g. Noodzakelijkheid van overgangsrecht. Ik mag niet nalaten, de juiste opmerkingen welke hieromtrent in het Verslag worden gemaakt, eenigzins verkort, weer te geven.

„Komt deze wet tot stand, dan moet aan de maatschappijen een behoorlijke termijn worden gelaten, om zich aan de nieuwe bepalingen aan te passen. De maatschappijen hier te lande zijn bij de onbeperkte vrijheid, welke de wet haar liet, niet alle ingericht op zoodanige wijze, dat wanneer eensklaps tot publicatie van tallooze bijzonderheden van het bedrijf werd overgegaan, dit voor haar geenerlei bezwaar 
zoude medebrengen. Vele maatschappijen zouden tegen zulk een publicatie, ook zonder dat haar eenige tijd werd gelaten, zeker niet het minste bezwaar hebben, maar er zijn er ook, voor wie de zaak anders staat. Aan insoliditeit behoeft hier nog geenszins te worden gedacht, maar er kunnen praktijken zijn aangenomen, methoden zijn gevolgd, die niet bestemd waren ter kennis van het groote publiek te komen en in de plaats waarvan men, indien het stelsel van publiciteit had bestaan, waarschijnlijk andere praktijken en methoden zou hebben gevolgd".

Opnieuw wordt hier de vinger op een wond gelegd. Door het ontbreken van wettelijke bepalingen is in het levensverzekeringsbedrijf een bandeloosheid ontstaan, waarvan de sporen in de jaarverslagen van verschillende maatschappijen zijn te ontdekken. Er zijn maatschappijen, die reeds nu meer publiceeren, dan de strengste wet kan eischen. Zii geven in haar jaarverslagen niet slechts volledige opgaaf van haar vermogen met een behoorlijke schatting naar den maatstaf op den datum der balans, maar ook een gedetailleerde uiteenzetting van de wijze, waarop de premiereserve is berekend met vermelding van sterftetafels en rentevoet. Daarbij wordt aangegeven, welk deel van den opslag voor onkosten is gebruikt, en welk deel nog beschikbaar is voor nog te verwachten kosten op de gesloten contracten. Wanneer zulk een verslag is geteekend door een actuaris van naam, en de schatting der bezittingen door een bevoegd accountant is geschied, heeft men alle reden om aan zulk een jaarverslag vertrouwen te schenken.

Voor deze maatschappijen kan een wet overbodig worden geacht, zij zullen na de invoering niets in haar werkwijze behoeven te veranderen.

Hiertegenover staan echter maatschappijen, zoowel grootere als kleine, wier verslagen slechts met schuilnesten zijn te vergelijken. Wel geven zij cijfers, doch deze moeten dienen om den waren toestand te verbergen. De premiereserve wordt berekend op grondslagen die niet worden genoemd; naar sterftetafels, die heeten uit eigen ondervinding te zijn afgeleid, maar aan de controle van deskundigen ontsnappen, omdat zij niet worden meegedeeld. Van een onkostenreserve voor reeds gesloten contracten is geen sprake; 
deze onkosten worden voldaan uit de premiën op nieuwe contracten, zoodat, wanneer de zaak om welke reden ook werd gesloten, voor verdere onkosten geen cent in kas zou zijn. Wat het vermogen der maatschappij betreft, hiervan vindt men slechts een globale opgave met de bijvoeging, dat de waarde is geschat naar den prijs bij inkoop, zoodat geen rekening is gehouden met de wisselende koersen op den datum der balans. Hoe zulk een handelwijze een dekmantel kan zijn voor allerlei meer of min gewaagde speculatiën met toevertrouwde gelden, behoeft waarlijk niet te worden aangetoond. $\mathrm{Zij}$ opent den weg tot het deelnemen aan en zelfs tot het vestigen van dubieuze ondernemingen, die echter voor aandeelhouders en verdere geïnteresseerden verborgen blijven. Men zegge nu niet: de concurrentie zal deze zaken wel aan het licht brengen. Want dit geschiedt niet, noch in de vakpers, noch in andere organen. Reeds nu zijn dergelijke misbruiken uit verschillende verslagen of andere gegevens af te leiden, maar nog nimmer is mij gebleken, dat daarop bij de aankondiging of beoordeeling dezer verslagen in gezaghebbende organen werd gewezen. Hier blijkt dus de noodzakelijkheid eener wettelijke regeling, waarbij alle verslagen ter beoordeeling aan een onafhankelijk bureau worden gezonden, dat een grondig onderzoek naar de juistheid en volledigheid dezer gegevens instelt, daarvan een verslag opstelt en dit ter algemeene kennis brengt. Dan kunnen die misbruiken niet langer verborgen blijven; dan zal het vertrouwen op de instelling niet het gevolg zijn van reclame, maar van goed gevestigd oordeel.

Ook in het verslag wordt op dergelijke misbruiken de aandacht gevestigd. Daarbij wordt echter een opmerking gemaakt, die ik minder kan beamen. Zij is de volgende: „worden, als gevolg van de publicatiën onmiddelijk na de invoering der wet verschijnende, van alle zijden aanvallen gedaan op maatschappijen, wier gepubliceerde gegevens kwetsbare punten aanbieden, dan heeft allicht een uittreding van verzekeringnemers op groote schaal plaats.

Tegen deze (door mij gespatieerde) woorden moet ik bezwaar maken. Het is juist het eigenaardige der contracten van levensverzekering, dat men zich daaraan niet of niet 
zonder groote schade kan onttrekken. Ik behoef slechts te wijzen op een contract van lijfrente tegen premie in eens; het eenmaal daarvoor gestorte bedrag krijgt men nooit terug; voor zijn verder leven is men van de maatschappij af hankelijk en kan men slechts hopen en bidden, dat zij, zoolang het leven van den verzekerde duurt, aan haar verplichting zal blijven voldoen. Zoo is het ook met contracten van weduwepensioer en kinderverzorging; van uittreden bij gerezen wantrouwen in de maatschappij kan geen kwestie zijn, want dan verliest men alle aanspraken op uitkeering aan na te laten betrekkingen. Daarom juist is hier een wettelijke regeling zoo dringend, veel meer dan voor maatschappijen of vereenigingen van anderen aard. Zoo kan men zonder schade treden uit een maatschappij voor brand- of ongevallen verzekering. Want hier loopt het contract slechts over enkele jaren, en kan men na afloop daarvan bij intusschen gerezen wantrouwen naar een andere maatschappij overgaan. Ook zijn daarbij in den regel niet zulke hooge geldelijke belangen betrokken, noch zulke hooge premiën te betalen als bij de levensverzekering. Het geldelijk beheer is daar niet zoo ingewikkeld en behoeft men geen deskundige te zijn, om over den toestand der maatschappij een oordeel te vellen.

Wel kan ik mij geheel vereenigen met de conclusie $(\S 4)$ van het verslag; zij luidt als volgt: „Algemeen was men van oordeel, dat dit wetsontwerp en de Memorie van Toelichting niet met de noodige zorg zijn samengesteld. De artikelen van het ontwerp zijn zeer gebrekkig geredigeerd en juridisch niet voldoende doordacht. Door zeer vele leden werd met nadruk de wenschelijkheid betoogd, dat de Regeering met de verdere bewerking van het wetsontwerp zooveel mogelijk voortgang zou maken. Het heeft zeer zeker op menig punt aanvulling en herziening noodig. Doch des te meer klemt de noodzakelijkheid dien arbeid zoo spoedig als eenigszins mogelijk is ter hand te nemen en tot een goed einde te brengen. Het ontbreken eener wettelijke regeling van het levensverzekeringsbedrijf heeft in de praktijk reeds ernstige gevolgen gehad; hoe eerder zij tot stand komt, des te beter". 
Volgt in het Verslag een gedetailleerde beoordeeling der artikelen, welke wij hier, na het reeds behandelde kunnen voorbijgaan. Doch een enkel woord over de bijgevoegde modelstaten mag niet ontbreken. Deze staten zijn 5 in aantal.

Staat I geeft een overzicht van de in het afgeloopen jaar gesloten en vervallen verzekeringen met opgave van de oorzaken van het vervallen; hierop is niets van belang aan te merken.

Staat II geeft een vergelijking van de verwachte sterfte (volgens de sterftetafel, waarop de berekening der wiskundige reserve is gebaseerd) met de feitelijke sterfte. Uitdrukkelijk moet hierbij worden gevoegd de aanwijzing, waar de gebruikte sterftetafels zijn te vinden, of, indien zij uit eigen ervaring zijn afgeleid, de meedeeling dezer sterftetafels met de gegevens, waaruit en de wijze waarop zij zijn afgeleid. Verder moet deze opgaaf zich niet bepalen tot personen, maar zich ook uitstrekken over vervallen kapitalen en renten. De splitsing in: "verzekerden bij overlijden", en "verzekerden bij leven" is minder doelmatig. Beter is de splitsing in "verzekerden met of zonder geneeskundig onderzoek", gelijk zij nu reeds in de verslagen van eenige maatschappijen voorkomt.

Staat III bevat de winst- en verliesrekening over het afgeloopen jaar. Omtrent deze wordt in het verslag opgemerkt, dat op sommige onbelangrijke punten al te groote specificatie wordt gevraagd, terwijl elders posten van belang worden bijeen gevoegd. Aangezien sommige groote maatschappijen jaren lang een winst- en verliesrekening hebben meegedeeld, waarop niets valt aan te merken, acht ik het hier den besten raad, deze in den modelstaat na te volgen.

Staat IV bevat de balans op 31 December van het afgeloopen jaar. Deze staat is onder alle de belangrijkste en ingewikkeldste. Hij wordt dan ook begeleid door vijf toelichtende staten. De eerste van dezen heeft betrekking op de wiskundige reserve onder aftrek van herverzekering. Gelijk in het verslag wordt opgemerkt is hij lang niet volledig. Want hij geeft niet de splitsing in de berekening met nettoen bruto- of tariefpremie, zoodat hier niet kan worden nagegaan, welk bedrag aan onkosten voor de reeds gesloten contracten alsnog beschikbaar is. Zulk een opgaaf is van hoog belang en mag derhalve niet ontbreken. 
In het Verslag wordt omtrent dezen Staat het volgende opgemerkt. „Andere leden meenden, dat hetgeen door dezen staat geeischt wordt, te ver gaat. Met name de sterftetafels oordeelden zij niet geschikt om te worden openbaar gemaakt. De maatschappijen besteden aan de vervaardiging daarvan vaak veel moeite en kosten en zij zijn dan ook eenigszins te vergelijken met fabrieksgeheimen. Moet men zijn sterftetafels aan de openbaarheid prijs geven, dan zal de prikkel om ze steeds te verbeteren voor een goed deel komen te vervallen. Hiertegen werd opgemerkt, dat publicatie der sterftetafels de techniek van het levensverzekeringsbedrijf vooruit zal brengen; achterlijke maatschappijen zullen daarvan veel kunnen leeren".

Hier wordt veel te groot vertrouwen in dergelijke eigen opgestelde, aan het oordeel van deskundigen onttrokken, sterftetafels toegekend. Slechts daarin zijn zij te vergelijken met fabrieksgeheimen, dat zij verborgen worden gehouden, omdat, wanneer zij het daglicht zagen, zou blijken op welke gebrekkige grondslagen $\mathrm{zij}$ berusten. $\mathrm{Zij}$ worden samengesteld en gebruikt om den schijn eener behoorlijke reserveberekening te bewaren, in gevallen waarin deze, naar bekende tafels berekend, het te kort aan reserve aan het licht zou brengen. Zoo is het een eerste vereischte, dat én rentevoet én sterftetafels, die tot grondslag der berekening zijn aangenomen in het volle licht worden geplaatst. Wanneer men in het ,Jaarboekje van de vereeniging voor levensverzekering" nagaat, welke sterftetafels door verschillende maatschappijen voor de reserveberekening worden gebruikt, dan staat men verbaasd niet slechts over het groote aantal, maar ook over de ondoelmatigheid van zoovelen. Zoo worden gebruikt tafels afgeleid uit de volkstelling, hetzij over het geheele rijk of over een bepaald gedeelte, welke tafels, afgescheiden van haar samenstelling, met het hier beoogde doel in geen, of liever in een zeer los verband staan.

In 1875 gaf de Directie der Nationale levensverzekeringsbank te Rotterdam een sterftetafel uit, afgeleid uit eigen waarnemingen bij deze maatschappij. Uit de achtereenvolgende jaarverslagen blijkt dat het wetenschappelijk onderzoek met groote zorg is voortgezet; de uitkomsten worden 
wel vergeleken met de sterfteverhoudingen van andere binnen- en buitenlandsche gegevens van gelijken aard, doch een nieuwere sterftetafel wordt niet afgeleid en is dus ook evenmin als de eerste bij de reserveberekening toegepast.

Ook de Hollandsche Societeit van levensverzekeringen te Amsterdam heeft uit eigen waarnemingen stertetafels saamgesteld, doch deze zijn beperkt tot de hoogere leeftijden en worden slechts toegepast voor berekening van lijfrenten voor mannen en vrouwen tezamen genomen. Voor kleine verzekeringen bestaan enkele tafels afgeleid uit waarnemingen bij begrafenisfondsen, waar geen streng gezondheidsonderzoek wordt vereischt.

Reeds verscheidene jaren bestaat een „vereeniging van wiskundige adviseurs bij Nederlandsche maatschappijen van levensverzekering. Haar voornaamste doel moest zijn, uit de samengevoegde ervaring dezer maatschappijen sterftetafels af te leiden, gelijk dit in het buitenland is geschied. Het doel heeft zij blijkens haar verslagen wel gehad, maar tot uitvoering is het niet gekomen. Aan den lust tot samenwerking der maatschappijen schijnt veel te ontbreken, anders zou de samengevoegde ervaring voldoende zijn om behoorlijke tafels op te stellen en voor het gebruik gereed te maken. Dit geldt ook voor verzekeringen binnen de keerkringen; voor de berekening van tarieven en reserve moet men zich vergenoegen met tafels afgeleid uit waarnemingen betreffende ambtenaren en officieren in onze koloniën.

Zoo blijkt uit het genoemde jaarboekje welk een chaotische verwarring heerscht, niet slechts in de wijze van reserveberekening, maar ook in de daarvoor aangenomen grondslagen, zoodat het waarlijk wel tijd wordt dat door een van regeeringswege opgericht centraalbureau deze aangelegenheid zoodanig worde geregeld, dat alle maatschappijen op gelijkvormige wijze haar financieële verslagen inrichten, en de uitkomsten daarvan met elkander kunnen vergeleken worden.

De tweede toelichting bij Staat IV heeft betrekking op de fondsen, die het kapitaal der maatschappij uitmaken. Hierbij moeten alle maatschappijen gedwongen worden tot volledige openbaarheid, gelijk deze reeds nu door ver- 
scheidene wordt toegepast. Want het geldt hier niet een eigendom dat ter vrije beschikking is der maatschappij, maar toevertrouwde gelden, die behoorlijk moeten verantwoord worden.

De waardeering van het bezit moet geschieden, voor zoover dit mogelijk is, naar den koers op den datum der balans, waarvan het wisselvallige kan worden opgeheven door een afzonderlijke reserve voor koersverandering. Waardeering naar den prijs bij aankoop moet, als leidende tot speculatie, uitgesloten blijven. Aandeelen in andere maatschappijen, hetzij deze in het binnen- of buitenland of in onze koloniën werken, moeten naar de waarde en niet naar de storting worden opgegeven; evenzoo de depôts, die als waarborg voor verzekeringen in het buitenland overeenkomstig de daar geldende wetten zijn gestort. Samenvoeging tot groepen, gelijk in het regeeringsvoorstel is voorgesteld, moet als bron van misleiding worden verboden, specificatie is hier onmisbaar. Onvoldoende moet geacht worden de verklaring van commissarissen, dat zij zich hebben overtuigd, hoe de genoemde bezittingen op den datum der balans werkelijk aanwezig waren. Zulk een verklaring moet door een bevoegd persoon, onafhankelijk van het bestuur der maatschappij, worden gecontroleerd en bevestigd. Aldus geschiedt o.a. bij het pensioenfonds voor weduwen en weezen van rijksambtenaren door een daartoe door den minister van financiën aangewezen hoofdambtenaar van zijn departement. Omtrent de volgende toelichtingen, betrekking hebbende op de "hypotheken" en "vaste eigendommen" kan ik volstaan met te verwijzen naar het Verslag, waarin hieromtrent nuttige wenken worden gegeven.

Staat $\mathrm{V}$ bevat de lijst van aandeelhebbers met vermelding voor ieder hunner van het aantal aandeelen en het hierop nog niet gestorte bedrag.

„Eenige leden meenden, dat door een publicatie van dezen aard ook al te zeer de belangen van de betrokken particulieren worden miskend". De juistheid dezer opmerking kan ik niet inzien.

Voorts wordt in het Verslag nog opgemerkt, dat de Staten zich niet inlaten met de kwestie der winstverdeeling aan verzekerden en het toch van belang is te weten, 
welk stelsel hierbij door de maatschappij wordt gevolgd.

Ook moest een opgaaf worden verstrekt van het percentage der premiën, dat voor toekomstige administratiekosten beschikbaar is onder bijvoeging, dat dit op eenvoudige wijze kan blijken uit een opgaaf van de verhouding der z.g. reservepremië tot de tariefpremie. $\mathrm{Nu}$, zoo eenvoudig is deze zaak niet; de netto-premiën worden namelijk op verschillende wijze en om allerlei bijkomstige zaken verhoogd. Zoo, behalve voor onkosten en winst, voor oorlogsrisico, voor acclimatisatie bij overgang van den verzekerde naar een kolonie; voor termijnbetaling; in vele gevallen voor onvoldoenden gezondheidstoestand volgens medisch advies. Ook worden de premiën wel eens verlaagd, b.v. voor geheelonthouders. Dan heeft men nog de afzonderlijke tarieven voor verblijf binnen de keerkringen. Het zou ondoenlijk zijn al deze verhoogingen te specificeeren en daarvoor afzonderlijke reserves te maken.

Deze zaak blijkt dus niet eenvoudig, maar zeer gecompliceerd te zijn; echter zal een behoorlijk verslag ook hierover het noodige licht doen opgaan.

Uit het voorgaande is op voldoende wijze gebleken, hoe het wetsontwerp een geheele omwerking moet ondergaan, alvorens te kunnen voldoen aan rechtmatige eischen. Niet slechts moet het worden uitgebreid en verscherpt, maar ook behoorlijk ingedeeld, gelijk dit in verschillende voorafgaande wetsontwerpen is geschied.

Zal daardoor een doeltreffende regeling van het bedrijf worden verkregen? Dit zij verre. Want hier worden slechts zaken geregeld; over personen wordt niet gehandeld. Een regeling van de verhouding, die de elementen van het bestuur betreft, moet voorafgaan. Dat zou zijn geschied, indien ware behandeld en aangenomen een wetsontwerp, dat reeds vier jaren geleden, n.l. 10 Februari 1910 bij Koninklijke boodschap door den toenmaligen minister van Justitie Nelissen werd ingediend en tot titel heeft: ,wijziging en aanvulling van de bepalingen in het Wetboek van Koophandel omtrent de naamlooze vennootschap van Koophandel en van daarmede samenhangende artikelen in dat wetboek en in het wetboek van Strafrecht". 
Voor de behandeling van dit ontwerp werd door de Tweede Kamer Staten Generaal een speciale commissie benoemd, die echter niets van zich liet hooren en door de vernieuwing der Kamer in het voorgaande jaar is vervallen. Ook van een wederindiening van dit wetsontwerp is nog niets gebleken, zoodat het nu als vervallen kan worden beschouwd.

In dat wetsontwerp werd voorgesteld een nieuwe regeling van de onderlinge verhouding tusschen de verschillende machten, die bij naamlooze vennootschappen, waaronder maatschappijen van levensverzekering zijn begrepen, haar werking uitoefenen. Dit geldt voornamelijk: aandeelhouders, bestuurders en commissarissen. Zoolang die verhouding niet behoorlijk is geregeld kan van een voldoende werking geen sprake zijn. Reeds herhaaldelijk is er op gewezen, hoeveel die regeling thans te wenschen overlaat: en dit is ook door verschillende catastrofen, waarop thans niet meer behoeft te worden ingegaan, duidelijk gebleken.

Zoo zal ook de beste regeling van het levensverzekeringsbedrijf krachteloos blijven, zoolang het gedeelte van het Wetboek van Koophandel, dat op het bestuur der naamlooze vennootschap betrekking heeft, ongewijzigd blijft.

In Engeland is het beheer toevertrouwd aan een „,board of trade" die de zaak bestuurt en verantwoordelijk is, terwijl de uitvoering wórdt overgelaten aan "manegers". Bij ons zijn "directeuren" de hoofdpersonen onder toezicht of controle van een college van Commissarissen. Dit college heeft dus geen wettelijke, slechts moreele verantwoordelijkheid voor den gang van zaken.

Bij de benoeming van commissarissen wordt in den regel meer gelet op naam en ambt, dan op kennis. Hoezeer het meer als een eerepost dan als een zaak van toewijding wordt beschouwd, blijkt wel hieruit, dat zelfs ministers in functie van zulk een college deel uitmaken. Een afgetreden directeur, die niet meer in staat is de daaraan verbonden werkzaamheden te vervullen, is nog goed genoeg om in het college van Commissarissen zitting te nemen. Hoe weinig waarde aan het toezicht van zulk een college wordt gehecht, blijkt ook hieruit, dat niet zelden de vader optreedt als commissaris eener instelling, waarvan de zoon directeur is! 
Dergelijke wanverhoudingen treffen te meer, waar het een maatschappij van levensverzekering geldt. De zaak is hier zoo ingewikkeld, dat buitengewone kennis van het vak wordt vereischt om in al haar bijzonderheden door te dringen. Om aan technische eischen te voldoen wordt niet zelden een hoogleeraar in de wiskunde in het college van toezicht opgenomen, in de meening dat deze voldoende voorlichting in de moeilijkheden der zaak kan geven. Maar ook hier komt men dikwijls bedrogen uit, want voor bekendheid met het ingewikkelde raderwerk is meer noodig dan zuiver mathematische bekwaamheid.

Volgens de statuten worden commissarissen door aandeelhouders benoemd; in werkelijkheid geschiedt het bij coöptatie. Soms wordt als meerdere waarborg bepaald, dat een of meer commissarissen door de verzekerden moeten verkozen worden. Doch dit is geheel als een wassen neus te beschouwen; hoe willen verzekerden, die elkander niet kennen en soms over verschillende landen zijn verspreid, zich met elkander beraden tot benoeming van een persoon, aan wien hun belangen zijn toe te vertrouwen? Over de machteloosheid van aandeelhouders tegenover het bestuur is reeds zoo dikwijls geschreven, dat het overbodig-kan geacht worden er thans op terug te komen. In hun machteloosheid toonen zij slechts belangstelling in de grootte van het dividend. Op straffe van ontevredenheid moet dit op peil gehouden worden; al moet de geheele balans worden omgewerkt, het oorspronkelijk verkregen nadeelig saldo moet in een voordeelig saldo worden omgezet. Dan blijven aandeelhouders rustig en komen niet ter algemeene vergadering, waar zij slechts de rol van figuranten kunnen vervullen. Wanneer men de jaarverslagen van zoo menige maatschappij met aandacht nagaat, dan blijkt in den regel uit het aantal uitgebrachte stemmen of vertegenwoordigde aandeelen, dat de zoogenaamde algemeene vergadering, die volgens de statuten de beslissing over de gewichtigste aangelegenheden en benoemingen in handen heeft, geheel of bijna geheel uit leden van het bestuur bestond! Zoo beslissen zij niet slechts hierin, maar ook over de hun zelven toe te kennen geldelijke belooning. 
Zoolang deze misstanden niet door strengere bepalingen en betere verhoudingen zijn weggenomen, is van een wet op het levensverzekeringsbedrijf weinig heil te wachten. Dan blijft slechts één radicaal middel over, dat reeds in Italie is toegepast, om namelijk het geheele bedrijf over te brengen naar den Staat, en het dus te doen overgaan in een staatsbedrijf. Slechts dit middel geeft afdoenden waarborg aan de verzekerden, dat de geldelijke offers, die zij zich voor na te laten betrekkingen of voor het onderhoud van den ouden dag moeten getroosten, ook werkelijk aan het doel zullen beantwoorden.
den Haag, Maart 1914.
P. van Geer. 